Proceedings

\title{
What is the untreated remission or natural recovery rate of peo- ple with depression? A systematic review and meta-analysis
}

\author{
Tesfa Mekonen 1,2,*, Sarah Ford 1, Gary Chan ${ }^{3}$, Leanne Hides 1,3 and Janni Leung 1,3 \\ 1 School of Psychology, The University of Queensland, Australia \\ 2 Psychiatry Department, Bahir Dar University, Ethiopia \\ 3 National Centre for Youth Substance Use Research, The University of Queensland, Australia
}

Publisher's Note: MDPI stays neutral with regard to jurisdictional claims in published maps and institutional affiliations.

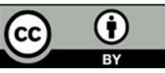

Copyright: (C) 2020 by the authors. Submitted for possible open access publication under the terms and conditions of the Creative Commons Attribution (CC BY) license (http://creativecommons.org/licenses/by/4.0/).

\begin{abstract}
The aim of this study was to estimate the remission (natural recovery) from untreated depression. We systematically searched EMBASE, PsycINFO, and PubMed supplemented with additional relevant sources to identify studies reporting natural recovery from untreated depression. Screening and data extraction were carried out by three independent reviewers. The data were synthesized using random-effects meta-analysis. we included 16 studies in this systematic review and meta-analysis. Most of the included studies were randomized waitlist control trials. The overall pooled remission from untreated depression was $22.6 \%$ with widely varied follow-up duration ranged from one month to six years. The remission was $11.4 \%$ within three months of follow-up period and $49.2 \%$ within six months or more duration. Remission within short untreated period is not common where 1 in 10 people may remitted within 3 months duration of untreated depression. Interpretation of the result should be considered in caution as the data from waitlist controls may represent mild-to-moderate depression.
\end{abstract}

Keywords: Spontaneous remission; Natural recovery; Untreated depression

\section{Introduction}

Depression is a common illness and leading cause of disease burden globally $[1,2]$. However, most cases of depression did not get treatment [3]. A community based survey from 15 countries reported that every 2 in 5 depression cases received any mental health service and the gap for effective treatment is as high as $90 \%$ [4]. Many barriers contribute to hinder people with depression to access treatment [5] and the perceived urgency of treatment planners could be diminished [6] due to spontaneous remission of some depression cases [7].

Understanding the outcomes of depression is critical due to the chronic and recurrence nature of the illness. Depression can be treated effectively[8,9]; up to $60 \%$ can achieve stable recovery and $70-85 \%$ may recovered at least once during their followup[10]. This recovery rate includes both treated and untreated depression. Treatment delay and longer duration of untreated depression can decrease this recovery rate, increase the risk of worse outcomes, and prolong illness duration [11]. In some cases, however, particularly in mild-to-moderate depression, remission may occur without treatment $[7,12]$.

As a significant number of people ( $\approx 5 \%)$ fulfilled criteria for depression in a year [2,3], it will be challenging to achieve $100 \%$ treatment coverage [7]. Estimating the proportion of depression cases remitted without treatment will help the policymakers to plan the urgent treatment target. It is also helpful for clinicians to consider a short watchful period before initiating active treatment for mild-to-moderate depression. Therefore, the objective of this systematic review and meta-analysis was to estimate the remission rates for untreated depression. 


\section{Methods}

This Systematic review was conducted in accordance with PRISMA guidelines and registered on PROSPERO, CRD42020198773.

\subsection{Eligibility criteria}

Studies were included if they were: 1 ) samples of people with depression, including depressive disorder, major depressive disorder, major depressive episode, depression assessed and categorized based on a validated measurement tool; 2) untreated, i.e. not exposed to treatment for their depression, including samples of participants on wait-list or natural cohorts who had not accessed treatment. Studies comparing the effects of intervention versus placebo for the treatment of depression were excluded because placebo is not classified as untreated in this review; 3) reported on the proportion of remission, i.e. the percentage of participants with rescinded diagnosis or no longer in the depressed category at given a certain time period. The review considered peer-reviewed papers in English issued from 2010 onwards to capture current evidence.

\subsection{Search strategy}

Databases searched included EMBASE, PsycINFO, and PubMed. Dates of coverage were 2010-01-01 to, the date of the search, 2020-07-20 to capture publications in the past 10 years. Supplementary sources included hand searches through PROSPERO, Google scholar, and secondary references of relevant papers.

We used a two-step approach to identify studies for inclusion. First, we systematically searched for existing reviews and screened the original studies included in relevant reviews identified to collect potential articles for inclusion. We then conducted a search for original studies. We did a title or abstract or MeSH Term search for studies using synonyms and related terms for the concept "Depression AND Untreated AND Remission". Limits applied were: Language: English AND Year: 2010 onwards, in accordance with our eligibility criteria.

\subsection{Study selection and data extraction}

Study selection and screening were carried out by three independent reviewers of this review. Conflicts were resolved by discussion and review against inclusion criteria. Independent reviewers extracted the data using a standardized data extraction form. Data were extracted on study details (study design, year of publication, country), participants characteristics (inclusion criteria, mean age, female proportion, sample size), and outcome details (assessment tool, the definition of remission, and proportion of untreated remission).

\subsection{Quality assessment}

The methodological qualities of the included studies were evaluated using a templet from existing review [7]. This template assesses the quality of the studies based on the sampling method, diagnostic assessment, untreated status of samples, definition of remission, and response rate.

\subsection{Synthesis of results}

We estimated the proportion of remission from untreated depression by the randomeffects model meta-analysis using DerSimonian and Laird method [13]. The variance of proportions was stabilized using Freeman-Tukey double arcsine transformation. Heterogeneity was assessed using the $\mathrm{I}^{2}$ statistics. We assessed the publication bias using the funnel plots and egger's test. Subgroup analysis was conducted by the duration of followup. All analyses were done using Stata version 16 (Stata Corporation, USA). 


\section{Results}

\subsection{Study characteristics}

We identified 57 studies eligible for full text assessment and 16 studies were included in the narrative review and meta-analysis (Fig. 1). All the included studies were from high-income countries, involved 1422 untreated participants with depression. From the 16 studies, 12 studies were waitlist control trials [14-25] and 4 studies were follow-up studies [26-29]. Studies were from community-based samples $(n=5)$, clinical settings $(n=5)$, internet based $(n=4)$, and school based $(n=2)$. The quality of studies ranged from $25-100 \%$.

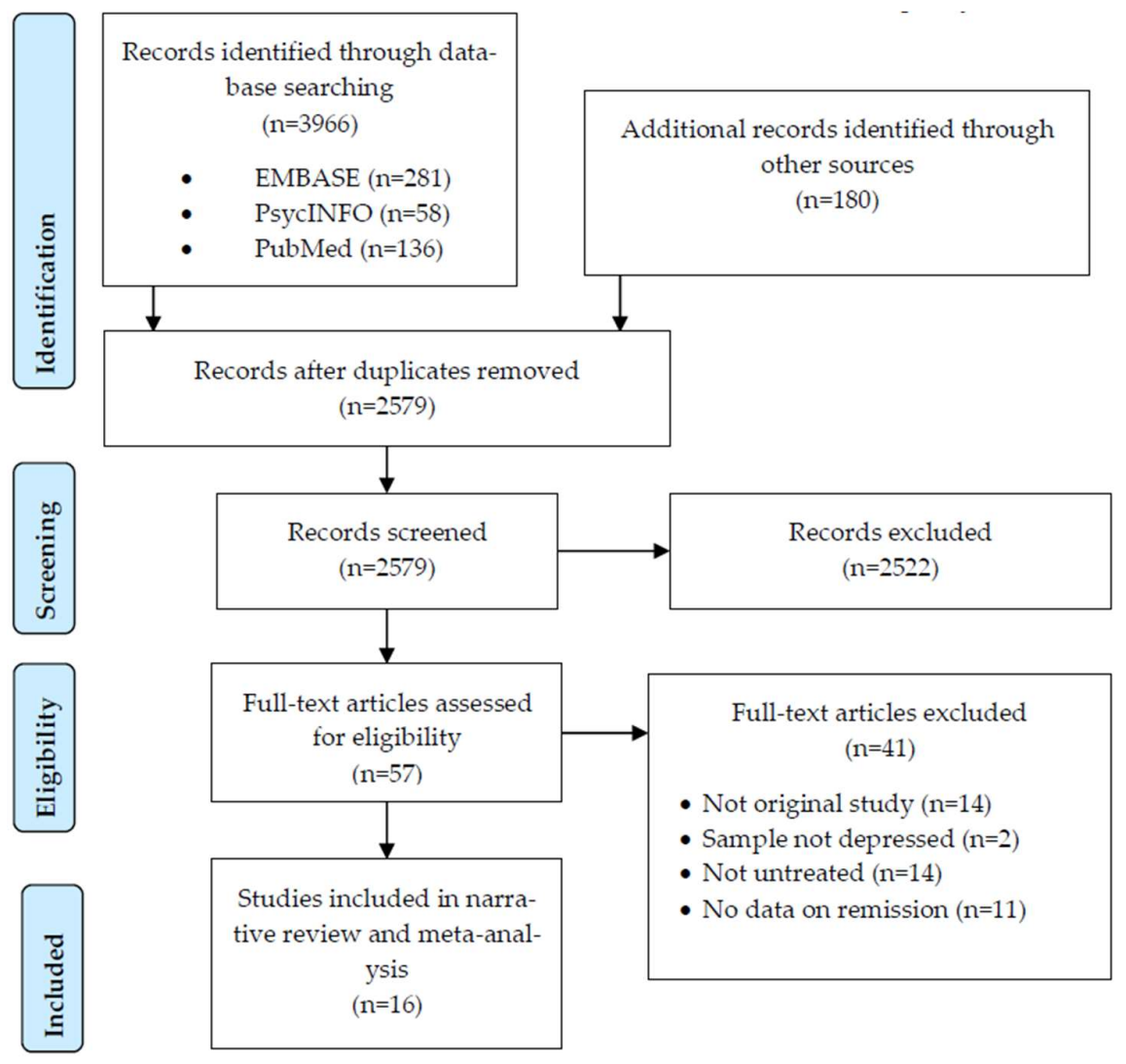

Figure 1. PRISMA flowchart for the search for original studies on remission among people with untreated depression.

\subsection{Remission from untreated depression}

The pooled estimate showed that the overall remission from untreated depression was $22.6 \%(11.9,35.2 \%)$ with significant between studies heterogeneity $\left(\mathrm{I}^{2}=95 \%, \mathrm{p}<\right.$ $0.001)$. Subgroup analysis by duration indicated that remission from untreated depression was $11.4 \%$ within 3 months and $49.2 \%$ within 6 months and above (Fig 2). The funnel plot is slightly asymmetric that shows few studies were missed in the right side. However, Egger's test $(\mathrm{p}=0.095)$ indicated no small study effect. 


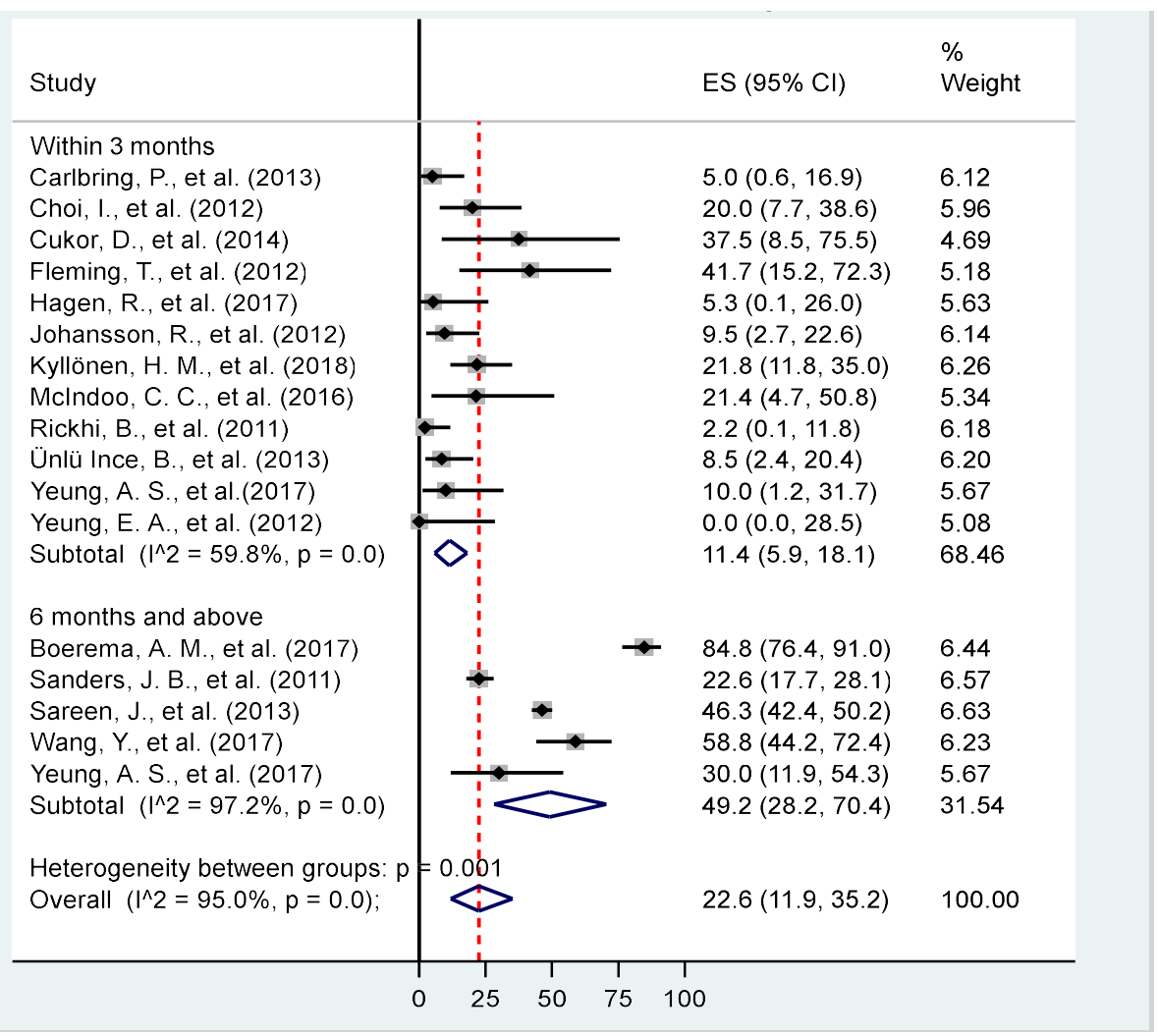

Figure 2. Remission from untreated depression by duration (forest plot).

\section{Discussion and conclusion}

This systematic review and meta-analysis involved 1422 untreated cases of depression in high-income countries. We did not found studies reporting remission from untreated depression in low- and middle-income countries. The pooled remission rate from untreated depression was $22.6 \%$. We reported substantial between studies heterogeneity which might limit the generalizability of our findings. The duration for untreated followup period widely varied from 1 month to 6 years. We found that $11.4 \%$ of untreated depression cases achieved remission within 3 months. This is lower than a previous review that reported $23 \%$ of spontaneous remission within 3 months [7]. In studies that conducted 6 months or longer follow-up, nearly half (49.2\%) of untreated depression cases remitted. This is in line with the previous review that reported $53 \%$ untreated remission within 1 year [7]. As the course and prognosis of depression varies and unpredictable [30], some of the patients remit without treatment while considerable number of cases did not improve even with treatment [31]. Though effective interventions are available, it is not clear yet to predict who will be most benefited from a specific intervention [31]. It might be plausible for clinicians to consider a short observational period for mild-to-moderate depressive symptoms before initiating active treatment.

This systematic review and meta-analysis mostly represent mild-to-moderate depression as most $(75 \%)$ of the included studies were from waitlist-control groups. This is also the case in the previous Whiteford et al review [7]. Most of the included studies in our review did not involve severe depression or excluded participants with suicidal ideation which may indicate severe cases. Hence, our findings of remission rate from untreated depression may not infer severe cases of depression.

\section{Conflicts of Interests: None}




\begin{abstract}
Acknowledgments: We would like to acknowledge the assistance of Miranda Newell, Librarian from The University of Queensland, for assistance with the search strategy. JL, TM, and SF acknowledges funding from The University of Queensland via a Development Fellowship, a Research Training Scholarship, and a Winter research scholarship, respectively.
\end{abstract}

\title{
References
}

1. Vos, T.; Lim, S.S.; Abbafati, C.; Abbas, K.M.; Abbasi, M.; Abbasifard, M.; Abbasi-Kangevari, M.; Abbastabar, H.; Abd-Allah, F.; Abdelalim, A., et al. Global burden of 369 diseases and injuries in 204 countries and territories, 1990-2019: a systematic analysis for the Global Burden of Disease Study 2019. The Lancet 2020, 396, 1204-1222, doi:https://doi.org/10.1016/S0140-6736(20)30925-9.

2. James, S.L.; Abate, D.; Abate, K.H.; Abay, S.M.; Abbafati, C.; Abbasi, N.; Abbastabar, H.; Abd-Allah, F.; Abdela, J.; Abdelalim, A., et al. Global, regional, and national incidence, prevalence, and years lived with disability for 354 diseases and injuries for 195 countries and territories, 1990-2017: a systematic analysis for the Global Burden of Disease Study 2017. The Lancet 2018, 392, 1789-1858, doi:https://doi.org/10.1016/S0140-6736(18)32279-7.

3. Thornicroft, G.; Chatterji, S.; Evans-Lacko, S.; Gruber, M.; Sampson, N.; Aguilar-Gaxiola, S.; Al-Hamzawi, A.; Alonso, J.; Andrade, L.; Borges, G., et al. Undertreatment of people with major depressive disorder in 21 countries. The British journal of psychiatry : the journal of mental science 2017, 210, 119-124, doi:10.1192/bjp.bp.116.188078.

4. Vigo, D.; Haro, J.M.; Hwang, I.; Aguilar-Gaxiola, S.; Alonso, J.; Borges, G.; Bruffaerts, R.; Caldas-de-Almeida, J.M.; de Girolamo, G.; Florescu, S., et al. Toward measuring effective treatment coverage: critical bottlenecks in quality-and user-adjusted coverage for major depressive disorder. Psychol Med 2020, 10.1017/s0033291720003797, 1-11, doi:10.1017/s0033291720003797.

5. Roberts, T.; Miguel Esponda, G.; Krupchanka, D.; Shidhaye, R.; Patel, V.; Rathod, S. Factors associated with health service utilisation for common mental disorders: a systematic review. BMC Psychiatry 2018, 18, 262-262, doi:10.1186/s12888-018-1837-1.

6. Kohn, R.; Saxena, S.; Levav, I.; Saraceno, B. The treatment gap in mental health care. Bulletin of the World Health Organization 2004, 82, 858-866, doi:/s0042-96862004001100011.

7. Whiteford, H.A.; Harris, M.G.; McKeon, G.; Baxter, A.; Pennell, C.; Barendregt, J.J.; Wang, J. Estimating remission from untreated major depression: a systematic review and meta-analysis. Psychol Med 2013, 43, 1569-1585, doi:10.1017/s0033291712001717.

8. Patel, V.; Araya, R.; Chatterjee, S.; Chisholm, D.; Cohen, A.; De Silva, M.; Hosman, C.; McGuire, H.; Rojas, G.; van Ommeren, M. Treatment and prevention of mental disorders in low-income and middle-income countries. Lancet (London, England) 2007, 370, 991-1005, doi:10.1016/s0140-6736(07)61240-9.

9. Linde, K.; Sigterman, K.; Kriston, L.; Rücker, G.; Jamil, S.; Meissner, K.; Schneider, A. Effectiveness of psychological treatments for depressive disorders in primary care: systematic review and meta-analysis. Ann Fam Med 2015, 13, 56-68, doi:10.1370/afm.1719.

10. Steinert, C.; Hofmann, M.; Kruse, J.; Leichsenring, F. The prospective long-term course of adult depression in general practice and the community. A systematic literature review. J Affect Disord 2014, 152-154, 65-75, doi:10.1016/j.jad.2013.10.017.

11. Ghio, L.; Gotelli, S.; Marcenaro, M.; Amore, M.; Natta, W. Duration of untreated illness and outcomes in unipolar depression: A systematic review and meta-analysis. Journal of Affective Disorders 2014, 152-154, 45-51, doi:https://doi.org/10.1016/j.jad.2013.10.002.

12. Posternak, M.A.; Miller, I. Untreated short-term course of major depression: a meta-analysis of outcomes from studies using wait-list control groups. Journal of Affective Disorders 2001, 66, 139-146, doi:https://doi.org/10.1016/S0165-0327(00)00304-9.

13. Nyaga, V.N.; Arbyn, M.; Aerts, M. Metaprop: a Stata command to perform meta-analysis of binomial data. Archives of Public Health 2014, 72, 39, doi:10.1186/2049-3258-72-39.

14. Carlbring, P.; Hägglund, M.; Luthström, A.; Dahlin, M.; Kadowaki, Å.; Vernmark, K.; Andersson, G. Internet-based behavioral activation and acceptance-based treatment for depression: a randomized controlled trial. J Affect Disord 2013, 148, 331-337, doi:10.1016/j.jad.2012.12.020.

15. Kyllönen, H.M.; Muotka, J.; Puolakanaho, A.; Astikainen, P.; Keinonen, K.; Lappalainen, R. A brief Acceptance and Commitment Therapy intervention for depression: A randomized controlled trial with 3-year follow-up for the intervention group. Journal of Contextual Behavioral Science 2018, 10, 55-63, doi:10.1016/j.jcbs.2018.08.009.

16. McIndoo, C.C.; File, A.A.; Preddy, T.; Clark, C.G.; Hopko, D.R. Mindfulness-based therapy and behavioral activation: A randomized controlled trial with depressed college students. Behav Res Ther 2016, 77, 118-128, doi:10.1016/j.brat.2015.12.012.

17. Rickhi, B.; Moritz, S.; Reesal, R.; Xu, T.J.; Paccagnan, P.; Urbanska, B.; Liu, M.F.; Ewing, H.; Toews, J.; Gordon, J., et al. A spirituality teaching program for depression: a randomized controlled trial. Int J Psychiatry Med 2011, 42, 315-329, doi:10.2190/PM.42.3.f. 
18. Ünlü Ince, B.; Cuijpers, P.; van 't Hof, E.; van Ballegooijen, W.; Christensen, H.; Riper, H. Internet-based, culturally sensitive, problem-solving therapy for Turkish migrants with depression: randomized controlled trial. J Med Internet Res 2013, 15, e227, doi:10.2196/jmir.2853.

19. Yeung, A.S.; Feng, R.; Kim, D.J.H.; Wayne, P.M.; Yeh, G.Y.; Baer, L.; Lee, O.E.; Denninger, J.W.; Benson, H.; Fricchione, G.L., et al. A Pilot, Randomized Controlled Study of Tai Chi With Passive and Active Controls in the Treatment of Depressed Chinese Americans. J Clin Psychiatry 2017, 78, e522-e528, doi:10.4088/JCP.16m10772.

20. Choi, I.; Zou, J.; Titov, N.; Dear, B.F.; Li, S.; Johnston, L.; Andrews, G.; Hunt, C. Culturally attuned Internet treatment for depression amongst Chinese Australians: A randomised controlled trial. Journal of Affective Disorders 2012, 136, 459-468, doi:https://doi.org/10.1016/j.jad.2011.11.003.

21. Fleming, T.; Dixon, R.; Frampton, C.; Merry, S. A Pragmatic Randomized Controlled Trial of Computerized CBT (SPARX) for Symptoms of Depression among Adolescents Excluded from Mainstream Education. Behavioural and Cognitive Psychotherapy 2012, 40, 529-541, doi:10.1017/S1352465811000695.

22. Yeung, E.A.; Lepoutre, W.V.; Wayne, L.P.; Yeh, L.G.; Slipp, L.L.; Fava, L.M.; Denninger, L.J.; Benson, L.H.; Fricchione, L.G. Tai Chi Treatment for Depression in Chinese Americans: A Pilot Study. American Journal of Physical Medicine E Rehabilitation 2012, 91, 863-870, doi:10.1097/PHM.0b013e31825f1a67.

23. Johansson, R.; Sjöberg, E.; Sjögren, M.; Johnsson, E.; Carlbring, P.; Andersson, T.; Rousseau, A.; Andersson, G. Tailored vs. Standardized Internet-Based Cognitive Behavior Therapy for Depression and Comorbid Symptoms: A Randomized Controlled Trial. PLOS ONE 2012, 7, e36905, doi:10.1371/journal.pone.0036905.

24. Cukor, D.; Ver Halen, N.; Asher, D.R.; Coplan, J.D.; Weedon, J.; Wyka, K.E.; Saggi, S.J.; Kimmel, P.L. Psychosocial intervention improves depression, quality of life, and fluid adherence in hemodialysis. Journal of the American Society of Nephrology 2014, 25, 196-206.

25. Hagen, R.; Hjemdal, O.; Solem, S.; Kennair, L.E.O.; Nordahl, H.M.; Fisher, P.; Wells, A. Metacognitive therapy for depression in adults: a waiting list randomized controlled trial with six months follow-up. Frontiers in Psychology 2017, 8, 31.

26. Sanders, J.B.; Bremmer, M.A.; Comijs, H.C.; Deeg, D.J.; Lampe, I.K.; Beekman, A.T. Cognitive functioning and the natural course of depressive symptoms in late life. Am J Geriatr Psychiatry 2011, 19, 664-672, doi:10.1097/JGP.0b013e3181f7d8e9.

27. Sareen, J.; Henriksen, C.A.; Stein, M.B.; Afifi, T.O.; Lix, L.M.; Enns, M.W. Common mental disorder diagnosis and need for treatment are not the same: findings from a population-based longitudinal survey. Psychol Med 2013, 43, 1941-1951, doi:10.1017/s003329171200284x.

28. Boerema, A.M.; ten Have, M.; Kleiboer, A.; de Graaf, R.; Nuyen, J.; Cuijpers, P.; Beekman, A.T.F. Demographic and need factors of early, delayed and no mental health care use in major depression: A prospective study. BMC psychiatry 2017, 17, doi:10.1186/s12888-017-1531-8.

29. Wang, Y.; Henriksen, C.A.; Ten Have, M.; de Graaf, R.; Stein, M.B.; Enns, M.W.; Sareen, J. Common Mental Disorder Diagnosis and Need for Treatment are Not the Same: Findings from the NEMESIS Study. Administration and policy in mental health 2017, 44, 572-581, doi:10.1007/s10488-016-0745-2.

30. Malhi, G.S.; Mann, J.J. Depression. The Lancet 2018, 392, 2299-2312, doi:https://doi.org/10.1016/S0140-6736(18)31948-2.

31. Cuijpers, P.; Stringaris, A.; Wolpert, M. Treatment outcomes for depression: challenges and opportunities. Lancet Psychiatry 2020, 7, 925-927, doi:10.1016/s2215-0366(20)30036-5. 